\title{
Serum S100A12 and Progression of Coronary Artery Calcification Over 4 Years in Hemodialysis Patients
}

\author{
Yin-na Wang Yi Sun Ying Wang Yan-li Jia \\ Division of Nephrology, Fu Xing Hospital, Capital Medical University, Beijing, China
}

\section{Key Words}

S100A12 - Vascular calcification · Coronary artery

calcification · Hemodialysis

\begin{abstract}
Background/Aim: Vascular calcification is common and contributes to increased cardiovascular mortality in hemodialysis (HD) patients. In this prospective study, we aimed to investigate the associations of serum S100A12 in the presence of severe coronary artery calcification (CAC) and the progression of CAC in HD patients. Methods: Sixty maintenance HD patients and 30 controls were enrolled. Serum S100A12 levels were measured using ELISA. CAC scores (CACs) were measured twice at a 4-year interval using multislice spiral CT. The HD patients were classified as rapid progressors or slow progressors according to the change in the CACs across these 2 measurements ( $\triangle C A C s$ ). Results: The incidences of rapid progression of CAC in patients with baseline $C A C s \leq 10, C A C s>10$ and $C A C s>400$ were $12.5,40.0$ and $64.3 \%$, respectively. Both baseline and 4-year serum S100A12 levels were significantly higher in the rapid progressors than in the slow progressors (medians of $45.6 \mathrm{vs} .30 .2 \mathrm{ng} / \mathrm{ml}, \mathrm{p}<$ 0.001 and 62.3 vs. $39.4 \mathrm{ng} / \mathrm{ml}, \mathrm{p}=0.002$, respectively). The serum S100A12 levels were significantly correlated with baseline CACs ( $r=0.466, p<0.001)$, 4-year CACs $(r=0.440$, $p<0.001)$ and $\triangle C A C s(r=0.392, p<0.001)$. Importantly, the $\triangle C A C s$ were significantly correlated with $\triangle S 100 A 12$ levels
\end{abstract}

(c) 2015 S. Karger AG, Basel

0250-8095/15/0421-0004\$39.50/0
( $r=0.396, p<0.001)$. Logistic regression analysis revealed that the serum S100A12 level was as an independent determinant of the presence of severe CAC and that the increment in the serum S100A12 level was a factor that was significantly independently associated with the progression of CAC. Conclusions: Serum S100A12 levels were significantly associated with the presence of severe $C A C$, and the increment in serum S100A12 levels was an independent determinant of the progression of CAC.

(c) 2015 S. Karger AG, Basel

\section{Introduction}

Cardiovascular disease (CVD) is the major cause of morbidity and mortality in patients with chronic kidney disease (CKD), particularly in hemodialysis (HD) patients. The mortality due to CVD in patients with endstage renal disease is 10 - to 40 -fold higher than that in the general population $[1,2]$. Vascular calcification is common and contributes to increased cardiovascular mortality in HD patients [3]. Therefore, the risk assessment for the presence and progression of vascular calcification could be of major clinical importance.

S100A12, also known as an extracellular newly identified receptor for advanced glycation end product binding protein (EN-RAGE), is a member of the S100 family of calcium-binding proteins that is predominantly expressed

\section{KARGER 125}

E-Mail karger@karger.com

www.karger.com/ajn
Yin-na Wang

Division of Nephrology, Fu Xing Hospital

Capital Medical University

Beijing 100038 (China)

E-Mail wang_yinna@163.com 
and secreted by granulocytes [4-6]. The binding of S100A 12 to the receptor for advanced glycation end product (RAGE) activates intracellular signaling cascades that lead to proinflammatory responses in target cells including the upregulation of adhesion molecules on the endothelium [4-6]. High concentrations of S100A12 are found in various inflammatory compartments, and serum S100A12 concentrations are increased in inflammatory diseases and correlated with the disease activity $[7,8]$.

S100A12 has also been found to be positively correlated with the carotid intima-media thickness of patients on $\mathrm{HD}$ and peritoneal dialysis [6,9]. Additionally, S100A12 has been identified as an independent predictor of the prevalence of CVD and cardiovascular-related mortality in HD patients $[10,11]$. However, information regarding the relationships of S100A12 with vascular calcification and the progression of vascular calcification in HD patients remains scarce and uncertain. Therefore, the present prospective study aimed to investigate the correlations of serum S100A12 levels with the presence and progression of vascular calcification by assessing the trends and dynamics of the changes in coronary artery calcification (CAC) scores (CACs) using multislice spiral CT (MSCT) in patients on maintained HD.

\section{Materials and Methods}

This study was approved by the Ethics Committees on Human Research of our hospital, and all subjects provided informed consent.

\section{Study Population}

Of the 128 patients undergoing maintenance $\mathrm{HD}$ in the Fu Xing Hospital, Capital Medical University (Beijing, China), 60 patients who had been treated for at least 6 months gave their written informed consent to enroll in this study. The underlying renal disorders were diabetic nephropathy (26.7\%) and non-diabetic nephropathy diseases that included chronic glomerulonephritis (38.3\%), hypertensive nephrosclerosis (21.7\%), chronic interstitial nephritis (8.3\%), polycystic kidney disease (3.3\%) and unknown etiologies (1.7\%). Histories of CVD were noted in 23 patients (38.3\%). All patients were receiving conventional 4 - to 5 -hour dialysis treatments 3 times per week and were clinically stable for at least 1 month prior to the baseline assessment (i.e. they exhibited no symptoms of acute coronary events, neoplasms or infectious or noninfectious inflammatory disease). The average dose of dialysis $(\mathrm{Kt} / \mathrm{V})$ was $1.40 \pm 0.22$. Thirty healthy volunteers ( 16 men and 14 women, mean age $65.2 \pm$ 7.8 years) were also enrolled as a control group. There were no differences in the age or gender distributions between the 2 groups. None of the control subjects had histories of hypertension, diabetes mellitus, cardiovascular disorder, cerebrovascular disease, kidney disease, cancer or acute or chronic infection, and they were receiving no medications at the time of the study.

\section{Clinical and Laboratory Measurements}

Peripheral venous blood was obtained from all subjects in 12hour fasting conditions. The blood samples were collected from the antecubital vein in the control subjects and from the vascular access in the HD patients on the morning of a routine dialysis day. The blood samples were immediately centrifuged within $20 \mathrm{~min}$ at $3,000 \mathrm{~g}$ for $10 \mathrm{~min}$ and stored at $-80^{\circ} \mathrm{C}$ for subsequent assay. The serum creatinine ( $\mathrm{SCr}$ ), albumin, electrolytes, calcium, phosphate, intact parathyroid hormone (iPTH), complete blood cell counts, hemoglobin, total cholesterol (TC), triglyceride (TG), low density lipoprotein cholesterol (LDL-C), high-density lipoprotein cholesterol (HDL-C), glycated hemoglobin Alc (HbAlc), ferritin and high-sensitivity C-reactive protein (hs-CRP) levels were measured. The mean values of 3 measurements taken during the 3 months before CACs measurements were used in analyses for HD patients. Serum S100A12 levels were determined twice using a commercially available ELISA kit (CUSABIO, Wuhan, China) at a 4-year interval. The intra-assay and inter-assay coefficients of variation were 8 and $10 \%$, respectively. Blood pressure was recorded 3 times after patients had rested for at least 10 min before dialysis sessions, and the average value of the 3 measurements was adopted. Moreover, medical records were carefully checked for prescriptions of vitamin $\mathrm{D}$ and phosphorus binders.

\section{CACs}

The CACs were measured twice at a 4-year interval using 64-slice CT (LightSpeed VCT XT; GE Healthcare, Waukesha, Wis., USA) for the HD patients and measured only once at baseline for the healthy volunteers. A dose of $12.5-25 \mathrm{mg}$ of the $\beta$ adrenergic blocking agent metoprolol was administered orally before MSCT if the patient's heart rate was more than 70 beats $/ \mathrm{min}$. Electrocardiogram-gated MSCT scan runs, consisting of the acquisition of 40 contiguous transverse 2-dimensional images of 3-mmthick sections at the level above the coronary artery origin to the cardiac apex, were performed. The exposure duration was $0.1 \mathrm{~s}$ per tomographic level, and the other parameters were $130 \mathrm{kVp}$ and $630 \mathrm{~mA}$. The images were acquired with electrocardiogram triggering at $71 \%$ of the $\mathrm{R}-\mathrm{R}$ interval during diastole and were obtained using a $26-\mathrm{cm}^{2}$ field of view and a $512 \times 512$ reconstruction matrix. Contrast agents were not used. A calcification was defined as a minimum of 2 adjacent pixels $\left(>0.52 \mathrm{~mm}^{2}\right)$ with a density over 130 Hounsfield units $[12,13]$. The peak intensities (in Hounsfield units) and areas (in square millimeters) of the individual calcifications were calculated. The total CACs calculations were based on formulas that incorporated the measurements of the total volume and area of the calcified lesions and their mean and maximum densities as described in the work of Agatston et al. [13]. The CACs of the HD patients were assessed at baseline and 4 years after the start of the study under the same standardized conditions by a single radiologist. The radiologist was blinded to the clinical and laboratory results of the patients. For each patient, the absolute change across these 2 measurements ( $\triangle \mathrm{CACs}$ ) was calculated.

\section{Statistical Analyses}

The statistical analyses were performed with SPSS 19.0. Data normality was analyzed using the Kolmogorov-Smirnov test. Normally distributed, continuous variables are presented as the means \pm SDs, and those with non-normal distributions are presented as the median and interquartile range. Categorical variables are presented as percentages. Comparisons between groups were 
Table 1. The baseline characteristics and clinical and laboratory features of the study patients

\begin{tabular}{|c|c|c|c|}
\hline & HD patients & Controls & $\mathrm{p}$ value \\
\hline Male/female & $60(30 / 30)$ & $30(16 / 14)$ & 0.77 \\
\hline Age, years & $63.5 \pm 14.2$ & $65.2 \pm 7.8$ & 0.64 \\
\hline Time on HD, months & $63.2 \pm 10.5$ & - & - \\
\hline $\mathrm{Kt} / \mathrm{V}$ & $1.40 \pm 0.22$ & - & - \\
\hline BMI, $\mathrm{kg} / \mathrm{m}^{2}$ & $23.75 \pm 3.73$ & $25.10 \pm 3.39$ & 0.20 \\
\hline Diabetes, \% & $16(26.7)$ & - & - \\
\hline Previous CVD, \% & $23(38.3)$ & - & - \\
\hline $\mathrm{SBP}, \mathrm{mm} \mathrm{Hg}$ & $152.4 \pm 32.5$ & $120.3 \pm 21.6$ & $<0.001$ \\
\hline Diastolic blood pressure, $\mathrm{mm} \mathrm{Hg}$ & $81.2 \pm 9.6$ & $79.2 \pm 8.4$ & 0.85 \\
\hline $\mathrm{SCr}, \mu \mathrm{mmol} / 1$ & $733.69 \pm 189.85$ & $103.20 \pm 120.86$ & $<0.001$ \\
\hline White blood cell count, $10^{9} / 1$ & $6.4 \pm 1.4$ & $6.1 \pm 1.0$ & 0.76 \\
\hline Hemoglobin, g/l & $108.2 \pm 11.5$ & $126.3 \pm 12.1$ & 0.004 \\
\hline Albumin, $g / 1$ & $38.48 \pm 2.62$ & $43.94 \pm 2.36$ & $<0.001$ \\
\hline $\mathrm{HbA} 1 \mathrm{c}, \%$ & $6.34 \pm 1.62$ & $5.40 \pm 1.51$ & 0.02 \\
\hline hs-CRP, mg/dl & $4.3(0.9-5.4)$ & $1.3(1.0-2.0)$ & 0.001 \\
\hline Ferritin, $\mu \mathrm{g} / \mathrm{l}$ & $343.5 \pm 88.3$ & - & - \\
\hline $\mathrm{TC}, \mathrm{mmol} / \mathrm{l}$ & $3.90 \pm 1.05$ & $4.55 \pm 1.07$ & $<0.001$ \\
\hline $\mathrm{TG}, \mathrm{mmol} / \mathrm{l}$ & $1.34 \pm 0.71$ & $1.79 \pm 0.87$ & 0.01 \\
\hline HDL-C, mmol/l & $1.03 \pm 0.29$ & $1.18 \pm 0.21$ & 0.15 \\
\hline LDL-C, mmol/l & $2.46 \pm 0.81$ & $2.95 \pm 0.86$ & 0.002 \\
\hline Calcium, mmol/l & $2.30 \pm 0.19$ & $2.17 \pm 0.10$ & 0.19 \\
\hline Phosphorus, mmol/l & $1.53 \pm 0.39$ & $1.03 \pm 0.12$ & 0.009 \\
\hline $\mathrm{Ca} \times \mathrm{P}, \mathrm{mmol}^{2} / 1^{2}$ & $3.52 \pm 0.99$ & $2.24 \pm 0.71$ & 0.01 \\
\hline iPTH, pg/ml & $370(42-1,992)$ & - & - \\
\hline Medications, $\%$ & & - & - \\
\hline Vitamin D & $20(33.3)$ & & \\
\hline Calcium-based phosphate binders & $46(76.7)$ & & \\
\hline Non-calcium-based phosphate binders & $3(5.0)$ & & \\
\hline Baseline S100A12, ng/ml & $35.2(22.0-51.5)$ & $10.5(6.9-18.7)$ & $<0.001$ \\
\hline 4 -year S100A12, ng/ml & $50.2(29.3-69.8)$ & - & - \\
\hline CACs & $278(53-1,390)$ & $67(0-731)$ & $<0.001$ \\
\hline
\end{tabular}

performed with the chi-square test for categorical variables, the $t$ test or analysis of variance for normally distributed, continuous variables and the Mann-Whitney $U$ test for non-normally distributed continuous variables. To examine the correlations between variables, the Pearson's tests were used for normally distributed data, and the Spearman's tests were used for non-normally distributed data. The variables for which values of $p$ were $<0.1$ in the univariate comparisons were included in a multivariate logistic regression analysis to predict CACs progression that utilized a significance level of 0.05 (entry/stay). All tests of significance were 2 -sided, and $p$ value $<0.05$ was considered statistically significant.

\section{Results}

\section{Background Characteristics}

The baseline characteristics, clinical and laboratory features of the patients and the controls are summarized in table 1 . There were no statistically significant differences between the 2 groups with respect to age, sex or body mass index (BMI). In addition to renal function, the CACs, serum S100A12 level, systolic blood pressure (SBP), hs-CRP, phosphorus and $\mathrm{HbAlc}$ level were significantly higher in the HD patients than in controls. In contrast, the hemoglobin, serum albumin, TC, TG and LDL-C levels were significantly lower in the HD patients than in the controls. At 4 years, 42 of 60 patients remained to be studied, and 18 patients were excluded for the following reasons: 14 patients due to death, 2 patients for refusal of follow-up MSCT, 1 patient moved to another dialysis unit and 1 patient due to incomplete blood sampling. The all-cause mortality in patients with baseline S100A12 levels above the median value $(\mathrm{n}=23)$ or below the median value $(\mathrm{n}=$ 37) were 39.1 and $13.5 \%$, respectively, with $p$ value of 0.023 . Moreover, the incidence of CVD during the 4 years was higher in patients with baseline S100A12 levels above the median value than in those with baseline S100A12 levels below the median value ( 34.8 vs. $8.1 \%, \mathrm{p}=0.024$ ). 
Table 2. Characteristics and clinical and laboratory features of patients grouped by baseline CACs

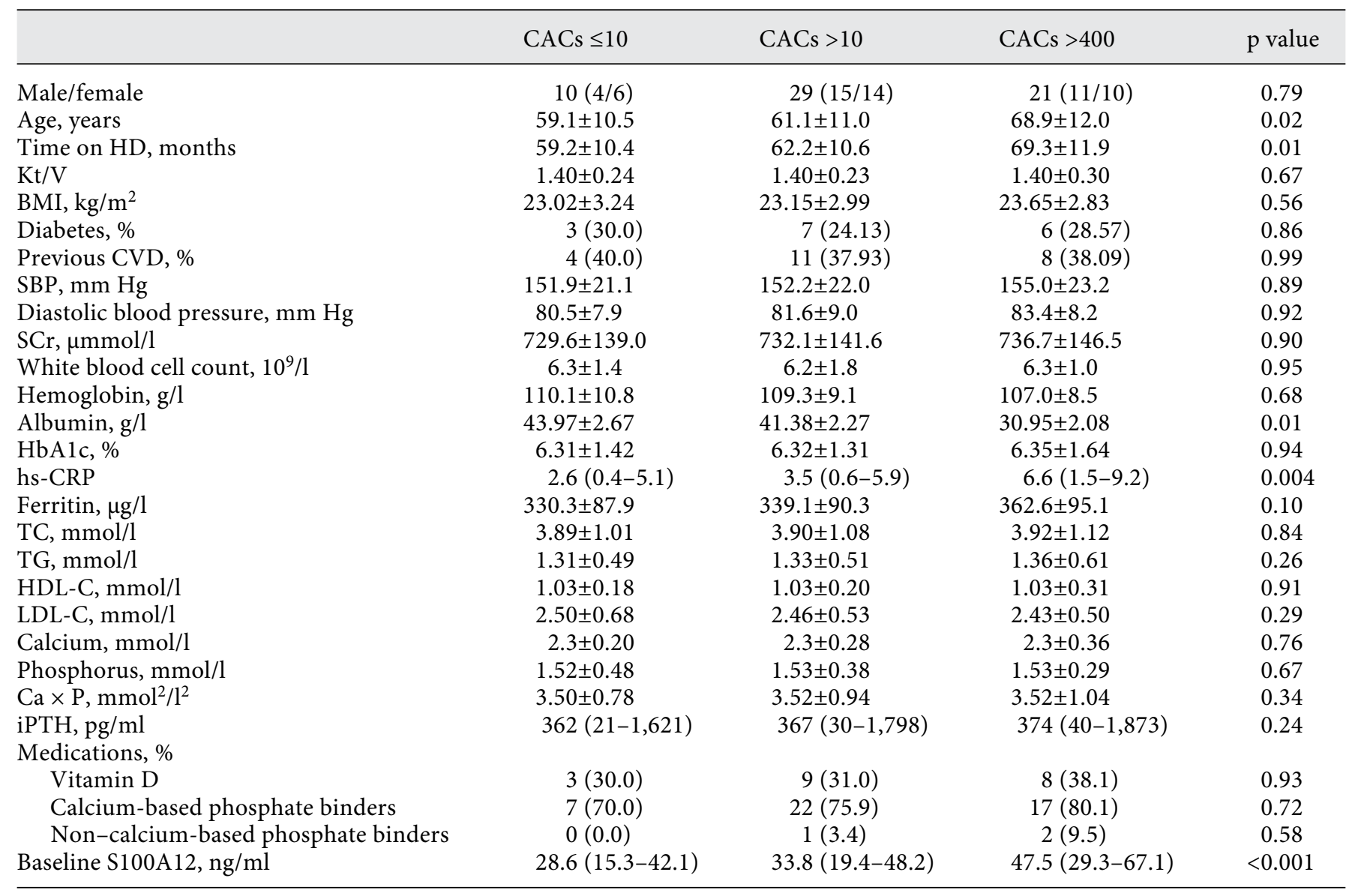

\section{Patients Grouped According to Baseline CACs and $\triangle C A C s$}

As described by the work of Rumberger et al. [14], patients were divided into 3 groups based on baseline CACs: CACs $\leq 10$ (no or minimal CAC, $\mathrm{n}=10$ ), CACs $>10$ (mild or moderate CAC, $\mathrm{n}=29$ ) and CACs $>400$ (severe CAC, $\mathrm{n}=21$ ). The demographic characteristics and baseline laboratory results of the 3 groups are presented in table 2 .

Follow-up CT scans were obtained after 4 years. The CACs progressed from $259(48-1,350)$ to $545(110-1,761)$ overall. Because 80 was the median $\triangle$ CACs value in our sample population, this value was chosen to divide the patients into rapid progressors with $\triangle \mathrm{CACs} \geq 80$ and slow progressors with $\triangle \mathrm{CACs}<80$. According to these criteria, $42.9 \%$ patients $(\mathrm{n}=18)$ were placed in the rapid progressor group. The incidences of rapid progression of CAC in the patients with baseline CACs $\leq 10$, CACs $>10$ and CACs $>400$ were $12.5,40.0$ and $64.3 \%$, respectively (fig. 1 ).

The comparisons of the rapid progressor and the slow progressor groups in terms of baseline characteristics and

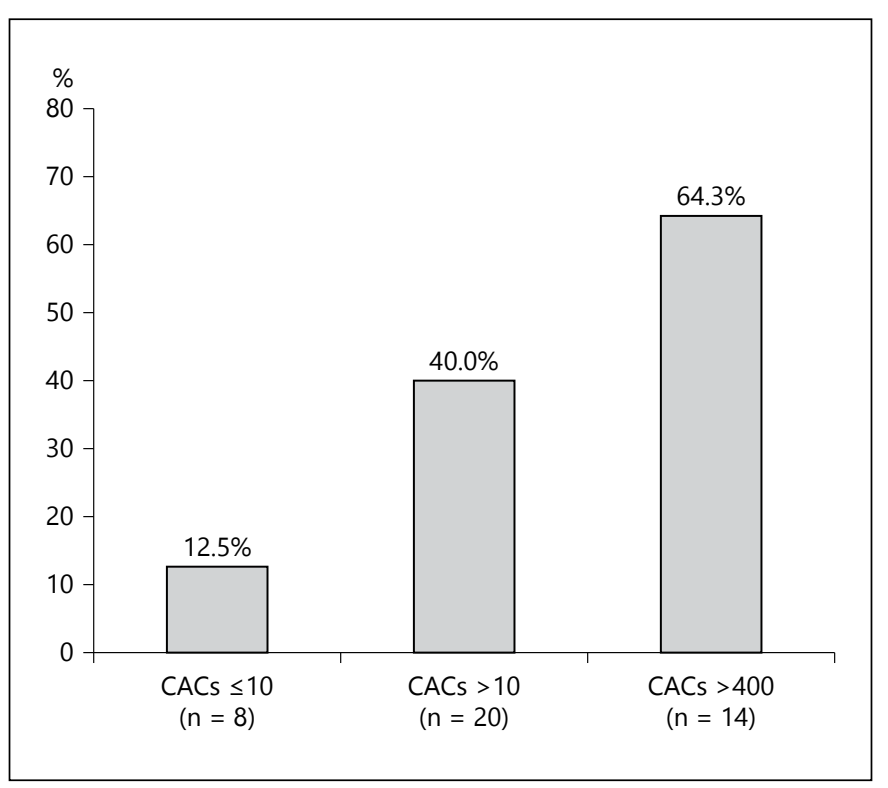

Fig. 1. Incidence of rapid progression of CAC according baseline CACs. 
Table 3. Characteristics and clinical and laboratory features of the study patients by subgroup

\begin{tabular}{|c|c|c|c|}
\hline & Rapid progressors & Slow progressors & $\mathrm{p}$ value \\
\hline Male/female & $18(8 / 10)$ & $24(10 / 14)$ & 0.86 \\
\hline Age, years & $69.1 \pm 12.3$ & $58.11 \pm 10.01$ & 0.004 \\
\hline Time on HD, months & $64.2 \pm 11.2$ & $62.3 \pm 10.1$ & 0.81 \\
\hline $\mathrm{Kt} / \mathrm{V}$ & $1.40 \pm 0.25$ & $1.40 \pm 0.18$ & 0.79 \\
\hline BMI, $\mathrm{kg} / \mathrm{m}^{2}$ & $23.11 \pm 3.45$ & $23.26 \pm 2.78$ & 0.49 \\
\hline Diabetes, \% & $7(38.9)$ & $9(40.9)$ & 0.93 \\
\hline Previous CVD & $10(55.6)$ & $13(59.1)$ & 0.91 \\
\hline SBP, mm Hg & $152.8 \pm 28.1$ & $151.2 \pm 27.0$ & 0.82 \\
\hline Diastolic blood pressure, $\mathrm{mm} \mathrm{Hg}$ & $82.5 \pm 8.4$ & $81.9 \pm 9.1$ & 0.90 \\
\hline Blood urea nitrogen, mmol/l & $24.2 \pm 3.9$ & $22.9 \pm 3.1$ & 0.45 \\
\hline $\mathrm{SCr}, \mu \mathrm{mmol} / \mathrm{l}$ & $740.6 \pm 159.4$ & $735.1 \pm 142.0$ & 0.61 \\
\hline White blood cell count, $10^{9} / 1$ & $6.5 \pm 1.7$ & $6.3 \pm 1.6$ & 0.58 \\
\hline Hemoglobin, g/l & $107.9 \pm 10.1$ & $108.8 \pm 9.6$ & 0.38 \\
\hline Albumin, $g / 1$ & $31.25 \pm 2.03$ & $41.83 \pm 2.72$ & 0.01 \\
\hline $\mathrm{HbA} 1 \mathrm{c}, \%$ & $6.35 \pm 1.29$ & $6.33 \pm 1.59$ & 0.79 \\
\hline hs-CRP & $6.1(1.4-8.9)$ & $2.8(0.5-5.7)$ & 0.003 \\
\hline Ferritin, $\mu \mathrm{g} / \mathrm{l}$ & $356.6 \pm 97.2$ & $338.1 \pm 91.5$ & 0.19 \\
\hline $\mathrm{TC}, \mathrm{mmol} / \mathrm{l}$ & $3.91 \pm 1.03$ & $3.93 \pm 1.06$ & 0.71 \\
\hline $\mathrm{TG}, \mathrm{mmol} / \mathrm{l}$ & $1.35 \pm 0.69$ & $1.31 \pm 0.58$ & 0.43 \\
\hline HDL-C, mmol/l & $1.03 \pm 0.18$ & $1.03 \pm 0.27$ & 0.87 \\
\hline LDL-C, mmol/l & $2.41 \pm 0.51$ & $2.49 \pm 0.63$ & 0.28 \\
\hline Calcium, mmol/l & $2.3 \pm 0.36$ & $2.3 \pm 0.25$ & 0.61 \\
\hline Phosphorus, mmol/l & $1.53 \pm 0.30$ & $1.52 \pm 0.45$ & 0.78 \\
\hline $\mathrm{Ca} \times \mathrm{P}, \mathrm{mmol}^{2} / \mathrm{l}^{2}$ & $3.55 \pm 1.02$ & $3.50 \pm 0.89$ & 0.19 \\
\hline $\mathrm{iPTH}, \mathrm{pg} / \mathrm{ml}$ & $377(42-1,926)$ & $368(31-1,993)$ & 0.31 \\
\hline \multicolumn{4}{|l|}{ Medications, \% } \\
\hline Vitamin D & $6(33.3)$ & $10(37.5)$ & 0.58 \\
\hline Calcium-based phosphate binders & $11(61.1)$ & $16(66.7)$ & 0.71 \\
\hline Non-calcium-based phosphate binders & $1(5.6)$ & $1(4.2)$ & 1.00 \\
\hline Baseline S100A12, ng/ml & $45.6(28.0-64.8)$ & $30.2(17.9-45.9)$ & $<0.001$ \\
\hline 4-year S100A12, ng/ml & $62.3(37.3-85.8)$ & $39.4(26.9-59.5)$ & 0.002 \\
\hline$\Delta \mathrm{S} 100 \mathrm{~A} 12, \mathrm{ng} / \mathrm{ml}$ & $17.2(5.8-25.2)$ & $7.9(3.5-11.8)$ & $<0.001$ \\
\hline$\Delta \mathrm{S} 100 \mathrm{~A} 12, \%$ & $43.4(16.3-55.1)$ & $23.2(10.4-32.9)$ & 0.002 \\
\hline Baseline CACs & $428(86-1,738)$ & $199(13-1,275)$ & $<0.001$ \\
\hline 4-year CACs & $708(183-2,305)$ & $259(29-1,229)$ & $<0.001$ \\
\hline
\end{tabular}

clinical and laboratory features are given in table 3. The rapid progressors were significantly older and had higher serum hs-CRP and lower serum albumin levels than the slow progressors. Both the baseline and 4-year serum S100A12 levels and CACs were significantly higher in the rapid progressors compared with those in the slow progressors (table 3). Furthermore, the absolute change and percentage change in S100A12 levels ( $\triangle \mathrm{S} 100 \mathrm{~A} 12)$ were also greater in the rapid progressors than in the slow progressors (fig. 2).

\section{Univariate Correlations between Baseline CACs,}

$\triangle C A C s$ and Serum S100A12 Levels with Other

Variables

Both the baseline CACs and $\triangle \mathrm{CACs}$ were positively correlated with age $(r=0.268$ and $r=0.251, p=0.01$ and $p=$
0.02 , respectively), time on $\mathrm{HD}(\mathrm{r}=0.248$ and $\mathrm{r}=0.209, \mathrm{p}=$ 0.02 and $p=0.03$, respectively), baseline S100A12 level ( $r=$ 0.466 and $\mathrm{r}=0.392$, respectively, $\mathrm{p}<0.001$ ), 4-year S100A12 $(\mathrm{r}=0.306$ and $\mathrm{r}=0.338, \mathrm{p}=0.001$ and $\mathrm{p}<0.001$, respectively), $\triangle \mathrm{S} 100 \mathrm{~A} 12(\mathrm{r}=0.411$ and $\mathrm{r}=0.396$, respectively, $\mathrm{p}<$ $0.001)$ and 4-year CACs $(r=0.391$ and $r=0.374$, respectively, $\mathrm{p}<0.001)$. The baseline CACs was also positively associated with $\triangle \mathrm{CACs}(\mathrm{r}=0.439, \mathrm{p}<0.001)$ and inversely correlated with serum albumin $(r=-0.281, \mathrm{p}=0.01)$ in the univariate analyses. However, no significant relationships were found between the CACs or $\triangle \mathrm{CACs}$ and the serum calcium, phosphorus, $\mathrm{Ca} \times \mathrm{P}$ product, $\mathrm{iPTH}$, serum hs-CRP, ferritin or the other variables (table 4).

The serum S100A12 levels were positively correlated with age $(r=0.259, p=0.01)$, time on dialysis $(r=0.218$, 
Table 4. Univariate correlations between baseline CACs, $\triangle$ CACs and serum S100A12 levels with other variables

\begin{tabular}{|c|c|c|c|c|c|c|}
\hline \multirow[t]{2}{*}{ Variable } & \multicolumn{2}{|c|}{ Baseline CACs } & \multicolumn{2}{|l|}{$\triangle \mathrm{CACs}$} & \multicolumn{2}{|c|}{ Baseline S100A12 } \\
\hline & $\begin{array}{l}\text { correlation } \\
\text { coefficient }\end{array}$ & $\mathrm{p}$ value & $\begin{array}{l}\text { correlation } \\
\text { coefficient }\end{array}$ & $\mathrm{p}$ value & $\begin{array}{l}\text { correlation } \\
\text { coefficient }\end{array}$ & $\mathrm{p}$ value \\
\hline Age & 0.268 & 0.01 & 0.251 & 0.02 & 0.259 & 0.01 \\
\hline Sex & 0.057 & 0.82 & 0.175 & 0.08 & 0.094 & 0.71 \\
\hline Time on HD & 0.248 & 0.02 & 0.209 & 0.03 & 0.218 & 0.02 \\
\hline SBP & 0.089 & 0.66 & 0.066 & 0.78 & 0.117 & 0.60 \\
\hline Diastolic blood pressure & -0.078 & 0.71 & -0.052 & 0.89 & -0.045 & 0.89 \\
\hline $\mathrm{SCr}$ & 0.034 & 0.91 & 0.043 & 0.93 & 0.056 & 0.85 \\
\hline White blood cell count & 0.080 & 0.69 & 0.091 & 0.64 & 0.146 & 0.45 \\
\hline Hemoglobin & 0.194 & 0.14 & 0.079 & 0.72 & 0.057 & 0.84 \\
\hline Albumin & -0.281 & 0.01 & -0.169 & 0.10 & -0.311 & $<0.001$ \\
\hline LDL-C & 0.189 & 0.17 & 0.119 & 0.46 & 0.154 & 0.42 \\
\hline hs-CRP & 0.129 & 0.47 & 0.136 & 0.29 & 0.308 & 0.001 \\
\hline Ferritin & 0.069 & 0.78 & 0.128 & 0.37 & 0.193 & 0.19 \\
\hline Calcium & -0.170 & 0.28 & -0.116 & 0.48 & -0.158 & 0.39 \\
\hline Phosphorus & 0.156 & 0.29 & 0.131 & 0.32 & 0.143 & 0.46 \\
\hline $\mathrm{Ca} \times \mathrm{P}$ product & 0.134 & 0.41 & 0.138 & 0.29 & 0.166 & 0.36 \\
\hline iPTH & 0.178 & 0.21 & 0.130 & 0.36 & 0.129 & 0.53 \\
\hline Vitamin D & 0.148 & 0.35 & 0.145 & 0.19 & 0.101 & 0.69 \\
\hline Calcium-based phosphate binders & -0.198 & 0.13 & -0.159 & 0.15 & -0.079 & 0.74 \\
\hline Non-calcium-based phosphate binders & -0.118 & 0.59 & -0.161 & 0.14 & -0.068 & 0.79 \\
\hline Baseline S100A12 & 0.466 & $<0.001$ & 0.392 & $<0.001$ & - & - \\
\hline
\end{tabular}

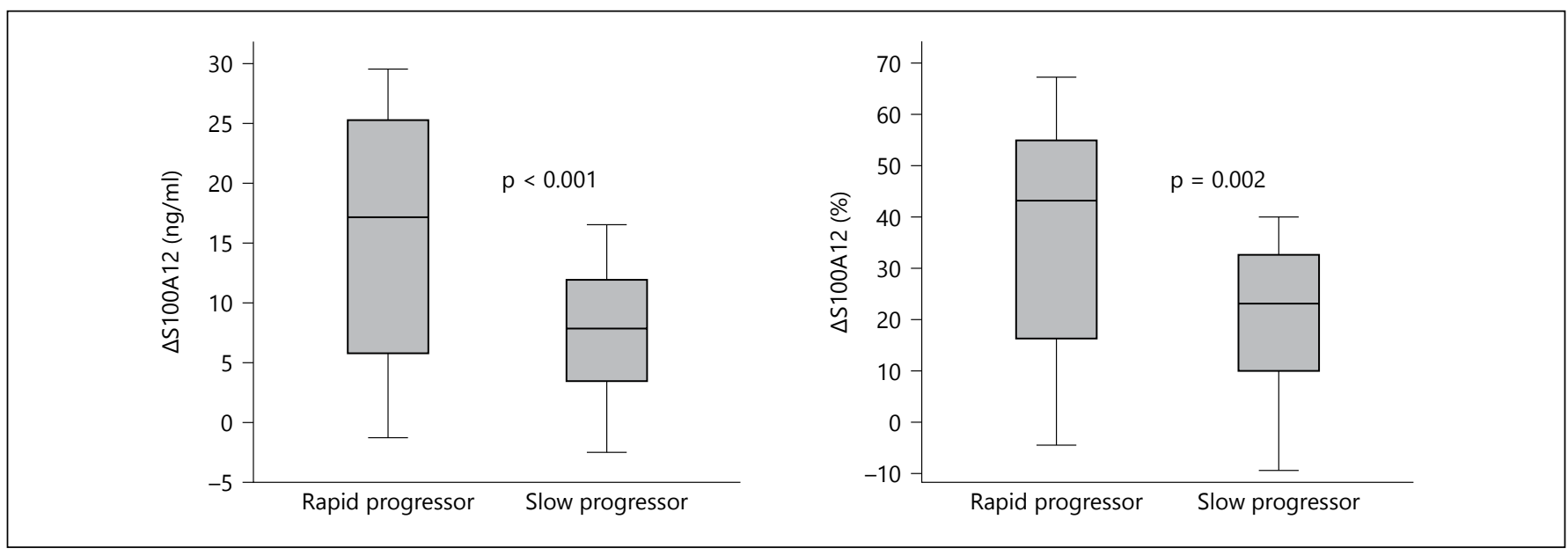

Fig. 2. Comparison of the rapid progressors and slow progressors in terms of the absolute change and percentage change in S100A12 ( $\triangle$ S100A 12$)$. 
$\mathrm{p}=0.02), 4$-year S100A12 $(\mathrm{r}=0.315, \mathrm{p}<0.001), \Delta \mathrm{S} 100 \mathrm{~A} 12$ $(\mathrm{r}=0.480, \mathrm{p}<0.001)$ and serum hs-CRP $(\mathrm{r}=0.308, \mathrm{p}=$ 0.001 ) and were negatively correlated with serum albumin levels $(r=-0.311, p<0.001)$. In addition to the baseline CACs, the serum S100A12 levels were also significantly correlated with the 4 -year CACs $(\mathrm{r}=0.440, \mathrm{p}<$ 0.001; table 4).

\section{Logistic Regression Analysis of the Independent} Variables Related to the Rapid Progression of CAC and the Presence of Severe CAC

To identify the variables that were independently related to the rapid progression of CAC, we performed a logistic regression analysis that included the model parameters that were previously identified in the univariate analyses (i.e. age, time on dialysis, serum hs-CRP, baseline CACs, baseline S100A12, $\Delta$ S100A12 and serum albumin) as independent variables and rapid progressor versus slow progressor as the dependent variable. The results revealed that only $\triangle$ S100A12 ( $\beta$ coefficient $=0.361$, $\mathrm{p}<0.001)$ and baseline CACs $(\beta$ coefficient $=0.439, \mathrm{p}<$ 0.001 ) were significantly independent determinants of the rapid progression of CAC. Baseline S100A12 was also an independent predictor when $\triangle S 100 \mathrm{~A} 12$ was not included in the logistic regression analysis $(\beta$ coefficient $=$ $0.287, \mathrm{p}=0.002$ ). Additionally, we performed a similar logistic regression analysis that included baseline CACs greater than or less than 400 as a dependent variable; the result revealed that age ( $\beta$ coefficient $=0.298, p=0.02)$, time on dialysis $(\beta$ coefficient $=0.392, \mathrm{p}<0.001)$ and baseline S100A12 level $(\beta$ coefficient $=0.467, \mathrm{p}<0.001)$ were independent predictors of the presence of severe CAC.

\section{Discussion}

The main findings of this prospective study were as follows: (1) the serum S100A12 levels of HD patients were high; (2) among the HD patients, the serum S100A12 levels of the patients who exhibited rapid progression of CAC were significantly higher than those who exhibited slow progression of CAC; (3) the serum S100A12 level was identified as an independent determinant of the presence of severe CAC and (4) the increment in the serum S100A12 level was identified as a significant independent factor associated with the progression of CAC. Therefore, we suggest that increased S100A12 levels and increments in S100A12 might contribute to the presence of severe $\mathrm{CAC}$ and the progression of CAC in HD patients.
Vascular calcification is common in chronic HD patients and is associated with increased cardiovascular mortality [3]. S100A12, as a member of the $\mathrm{S} 100 \mathrm{Ca}^{2+}$ binding protein family, is associated with acute/chronic inflammatory disorders. Evidence has shown that serum S100A12 levels are elevated in patients with several inflammatory diseases, including rheumatoid arthritis, Kawasaki disease and chronic inflammatory bowel diseases [15-17]. Recently, epidemiological studies of HD patients have identified serum S100A12 level as a significant independent determinant of carotid intimal-media thickness $[6,9]$ and as an independent predictor of the prevalence of CVD and cardiovascular-related mortality $[10,11]$. In a study of 5 CKD patients, plasma S100A12 was associated with inflammation and the presence of CVD and diabetes mellitus, and a 1-SD increase in the level of S100A12 was found to be associated with a $32 \%$ higher risk of all-cause mortality [18]. Our finding was similar to the above results. Furthermore, our study revealed elevated baseline serum S100A12 levels in patients with rapid progression of CAC. To some extent, the results of our study elucidate the higher prevalence of CVD and mortality among patients with higher serum S100A12 levels.

The mechanism by which HD patients with rapidly progressing of CAC possess elevated serum S100A12 levels remains unknown. Chronic inflammation is a common feature of uremic states and HD and might activate leukocytes or increase the synthesis and/or release of S100A12 via the modification of cytokines and/or other molecules [6]. This notion is supported by the recent finding of the strong correlation between S100A 12 mRNA in leucocytes and serum S100A12 concentrations in uremic CKD patients, particularly in those affected with CVD [19]. As systemic and local inflammation has been extensively implicated in the progression of calcific aortic valve disease [20], the elevated serum levels of S100A12 in HD patients with rapidly progressing CAC compared with those with slowly progressing CAC might be attributable to positive feedback or increased synthesis by much more activated leukocytes or cytokines.

Several studies have provided evidence suggesting that vascular calcification is mediated by S100A12. In a study by Hofmann Bowman et al. [21], vascular calcification and the expressions of bone morphogenetic protein-2 and other osteoblastic genes were found to be increased in the aortas of ApoE-null mice with the S100A12 transgene and in cultured vascular smooth muscle cells expressing S100A12. Additionally, these authors suggested that accelerated vascular calcification induced by S100A 12 is also mediated by oxidative stress because the inhibition
Wang/Sun/Wang/Jia 
of NADPH oxidase attenuates S100A12-mediated osteogenesis. In another study by Gawdzik et al. [22], increased vascular calcification in S100A12 transgenic mice subjected to CKD was observed compared to WT-CKD mice, while minimal vascular calcification was observed in S100A12 transgenic-sham mice. Moreover, this study suggested that the augmentation of vascular calcification by S100A12 depends on enhanced oxidative stress and RAGE- and NADPH-dependent increases in the expressions of osteoblastic genes, such as Runt-related transcription factor 2, bone morphogenetic protein-2 and bone Gla protein (also known as osteocalcin), in vascular smooth muscle cells. Very recently, a reduction in osteopontin mRNA was unexpectedly found in cardiac fibroblasts in response to recombinant S100A12 protein in a study by Yan et al. [23]. Because cytokines, inflammation and oxidative stress have been shown to increase osteopontin expression in vascular cells, the authors of this study speculated that the known proinflammatory signaling of S100A12 in combination with a reduction in the level of osteopontin (which is an important inhibitor of vascular mineralization) might lead to important insights about the mechanisms of S100A12-mediated calcification of vascular and valvular cells.

Some reports about the relationships between S100A12 and vascular calcification have recently been published. In a study by Kim et al. [24], plain X-ray images of the lateral lumbar spines of HD patients were studied to calculate semiquantitative vascular calcification scores. Serum S100A12 exhibited a trend toward a positive association with vascular calcification, but it was not found to be an independent predictor of vascular calcification in a multiple stepwise regression analysis. Additionally, another study by Kim et al. [9] revealed that plasma 100A12 is positively correlated with vascular calcification $(\mathrm{r}=$ $0.315, p=0.015$ ) in peritoneal dialysis patients. Moreover, using multiple stepwise regression analysis, these authors found that the plasma 100A12 exhibits a trend toward a positive correlation with vascular calcification, although this association did not reach significance. In our study, the serum S100A12 level was identified as an independent determinant of severe CAC. The inconsistent results between our study and those of Kim et al. [9,24] might be attributable, at least in part, to statistical reason. On one hand, the definitions of the dependent variables in the regression analyses were different. Kim et al. $[9,24]$ included CACs as a dependent variable in the regression analysis, while in our study, severe CAC was used as dependent variable. On the other hand, previous studies have suggested that the circulating soluble RAGE
(sRAGE) might be inversely associated with S100A12 protein $[25,26]$. Elevations in sRAGE might exert vasculoprotective effects by decreasing inflammatory cytokines and matrix metalloproteinases, while higher plasma S100A12 levels might be associated with amplified inflammatory responses and extensive vascular damage. For this reason, in the works by Kim et al. [9, 24], the effects of S100A12 on CAC might have been masked by the inclusion of sRAGE and S100A12 together in a single multiple stepwise regression analysis.

Previous studies have confirmed that CACs progression is associated with higher rates of cardiac event in non-uremic and CKD patients [27-29]. In a work based on CKD patients, every 10 units of CACs progression were found to be associated with a $3 \%$ increase in mortality per year [29]. Therefore, it is important to identify the factors that predict the progression of CAC. Our prospective study examined serum S100A12 and CACs measurements twice at a 4-year interval and found that increment in serum S100A12 levels was significantly correlated with the progression of CAC and might be an important predictor of CAC progression. To our knowledge, this is the first prospective and longitudinal study to investigate the effects of S100A12 on the progression of CAC.

It has been confirmed that the baseline level of vascular calcification is a strong determinant of the progression of vascular calcification. Block et al. [30] found that patients new to HD, with evidence of at least mild CAC at baseline, exhibited significant increases in CACs within 6 months of starting dialysis despite controlling for laboratory parameters of mineral metabolism. In another study by Sigrist et al. [29], progressive calcification was found to be significantly correlated with baseline CACs over 24 months $(\mathrm{r}=0.648, \mathrm{p}<0.001)$. Additionally, a recent study based on $78 \mathrm{HD}$ patients revealed that baseline CACs is positively associated with $\triangle$ CACs over 1-year intervals $(\mathrm{r}=0.45, \mathrm{p}<0.001)$ and is a significant factor in the prediction of the progression of CACs [31]. The results of our present study are consistent with these studies, and baseline CACs was also confirmed to be an independent determinant of the progression of vascular calcification.

It is noteworthy that there was no association between $\mathrm{CAC}$ and some traditional risk factors. Prior studies have reported multiple risk factors to be implicated in the development of CAC, including age, dialysis duration, serum phosphorus, calcium, diabetes and hypertension [12, 32]. However, no consistent and/or constant associations have been established. We adopt severe CAC as the dependent variable for multiple logistic regression analysis, and our population was characterized by good glycemic, 
blood pressure and mineral control, which may partly explain why there was no significant association between CAC and these risk factors. Nevertheless, the relatively small sample size may be the most probable reason for our results.

There are important limitations to the present study. Our sample size was relatively small, and we cannot draw solid conclusions. To confirm our findings, a larger patient group should be studied. Additionally, although age- and sex-matched controls were included in this study and multivariable logistic regression analysis was used, the confounding factors between groups could not be completely eliminated.

In conclusion, the serum S100A12 levels were significantly associated with the presence of severe CAC, and increments in serum S100A12 levels were an independent determinant of the progression of CACs over 4 years of follow-up. Serum S100A12 levels and increments in serum S100A 12 levels might be involved in the presence of severe CAC and the progression of CAC in HD patients.

\section{Acknowledgments}

This research was supported by the following 2 funds: 'Capital Medical University Preclinical Medicine - Clinical Medicine Research Cooperation Project' (14JL68) and the 'Scientific Research for Capital Medical Development' (2009-3195). We truly appreciate the radiologists in our hospital for their contributions to the measurement of CACs.

\section{Disclosure Statement}

The authors declare that there is no conflict of interests regarding the publication of this article.

\section{References}

1 Sarnak MJ, Levey AS, Schoolwerth AC, Coresh J, Culleton B, Hamm LL, McCullough PA, Kasiske BL, Kelepouris E, Klag MJ, Parfrey P, Pfeffer M, Raij L, Spinosa DJ, Wilson PW; American Heart Association Councils on Kidney in Cardiovascular Disease, High Blood Pressure Research, Clinical Cardiology, and Epidemiology and Prevention: Kidney disease as a risk factor for development of cardiovascular disease: a statement from the American Heart Association Councils on Kidney in Cardiovascular Disease, High Blood Pressure Research, Clinical Cardiology, and Epidemiology and Prevention. Circulation 2003;108:2154-2169.

2 Collins AJ: Cardiovascular mortality in endstage renal disease. Am J Med Sci 2003;325: 163-167.

3 London GM, Guérin AP, Marchais SJ, Métivier F, Pannier B, Adda H: Arterial media calcification in end-stage renal disease: impact on all-cause and cardiovascular mortality. Nephrol Dial Transplant 2003;18:17311740.

4 Hofmann MA, Drury S, Fu C, Qu W, Taguchi A, Lu Y, Avila C, Kambham N, Bierhaus A, Nawroth P, Neurath MF, Slattery T, Beach D, McClary J, Nagashima M, Morser J, Stern D, Schmidt AM: RAGE mediates a novel proinflammatory axis: a central cell surface receptor for S100/calgranulin polypeptides. Cell 1999;97:889-901.

5 Yang Z, Tao T, Raftery M, Youssef P, Di Girolamo N, Geczy CL: Proinflammatory properties of the human S100 protein S100A12. J Leukoc Biol 2001;69:986-994.

6 Mori Y, Kosaki A, Kishimoto N, Kimura T, Iida K, Fukui M, Nakajima F, Nagahara M, Urakami M, Iwasaka T, Matsubara H: In- creased plasma S100A12 (EN-RAGE) levels in hemodialysis patients with atherosclerosis. Am J Nephrol 2009;29:18-24.

7 Yang Z, Yan WX, Cai H, Tedla N, Armishaw C, Di Girolamo N, Wang HW, Hampartzoumian T, Simpson JL, Gibson PG, Hunt J, Hart P, Hughes JM, Perry MA, Alewood PF, Geczy CL: S100A12 provokes mast cell activation: a potential amplification pathway in asthma and innate immunity. J Allergy Clin Immunol 2007;119:106-114.

8 Mahajan N, Malik N, Bahl A, Dhawan V: Receptor for advanced glycation end products (RAGE) and its inflammatory ligand ENRAGE in non-diabetic subjects with pre-mature coronary artery disease. Atherosclerosis 2009;207:597-602.

9 Kim JK, Park S, Lee MJ, Song YR, Han SH, Kim SG, Kang SW, Choi KH, Kim HJ, Yoo TH: Plasma levels of soluble receptor for advanced glycation end products (sRAGE) and proinflammatory ligand for RAGE (ENRAGE) are associated with carotid atherosclerosis in patients with peritoneal dialysis. Atherosclerosis 2012;220:208-214.

10 Shiotsu Y, Mori Y, Nishimura M, Sakoda C, Tokoro T, Hatta T, Maki N, Iida K, Iwamoto $\mathrm{N}$, Ono $\mathrm{T}$, Matsuoka E, Kishimoto N, Tamagaki K, Matsubara H, Kosaki A: Plasma S100A12 level is associated with cardiovascular disease in hemodialysis patients. Clin J Am Soc Nephrol 2011;6:718-723.

11 Nakashima A, Carrero JJ, Qureshi AR, Miyamoto T, Anderstam B, Bárány P, Heimbürger O, Stenvinkel P, Lindholm B: Effect of circulating soluble receptor for advanced glycation end products (sRAGE) and the proinflammatory RAGE ligand (EN-RAGE, S100A12) on mortality in hemodialysis pa- tients. Clin J Am Soc Nephrol 2010;5:22132219.

12 Ozkok A, Kekik C, Karahan GE, Sakaci T, Ozel A, Unsal A, Yildiz A: FGF-23 associated with the progression of coronary artery calcification in hemodialysis patients. BMC Nephrol 2013;14:241.

13 Agatston AS, Janowitz WR, Hildner FJ, Zusmer NR, Viamonte M Jr, Detrano R: Quantification of coronary artery calcium using ultrafast computed tomography. J Am Coll Cardiol 1990;15:827-832.

14 Rumberger JA: Using noncontrast cardiac CT and coronary artery calcification measurements for cardiovascular risk assessment and management in asymptomatic adults. Vasc Health Risk Manag 2010;6:579-591.

15 Foell D, Kane D, Bresnihan B, Vogl T, Nacken W, Sorg C, Fitzgerald O, Roth J: Expression of the pro-inflammatory protein S100A12 (EN-RAGE) in rheumatoid and psoriatic arthritis. Rheumatology (Oxford) 2003;42:1383-1389.

16 Foell D, Ichida F, Vogl T, Yu X, Chen R, Miyawaki T, Sorg C, Roth J: S100A12 (EN-RAGE) in monitoring Kawasaki disease. Lancet 2003; 361:1270-1272.

17 Foell D, Kucharzik T, Kraft M, Vogl T, Sorg C, Domschke W, Roth J: Neutrophil derived human S100A12 (EN-RAGE) is strongly expressed during chronic active inflammatory bowel disease. Gut 2003;52:847-853.

18 Isoyama $\mathrm{N}$, Leurs $\mathrm{P}$, Qureshi AR, Bruchfeld A, Anderstam B, Heimburger O, Bárány $\mathrm{P}$, Stenvinkel P, Lindholm B: Plasma S100A12 and soluble receptor of advanced glycation end product levels and mortality in chronic kidney disease stage 5 patients. Nephrol Dial Transplant 2015;30:84-91. 
19 Hara M, Ando M, Morito T, Nokiba H, Iwasa Y, Tsuchiya K, Nitta K: S100A12 gene expression is increased in peripheral leukocytes in chronic kidney disease stage 4-5 patients with cardiovascular disease. Nephron Clin Pract 2013;123:202-208.

20 Rajamannan NM, Evans FJ, Aikawa E, GrandeAllen KJ, Demer LL, Heistad DD, Simmons CA, Masters KS, Mathieu P, O’Brien KD, Schoen FJ, Towler DA, Yoganathan AP, Otto CM: Calcific aortic valve disease: not simply a degenerative process: a review and agenda for research from the National Heart and Lung and Blood Institute Aortic Stenosis Working Group. Executive summary: calcific aortic valve disease - 2011. Circulation 2011;124:1783-1791.

21 Hofmann Bowman MA, Gawdzik J, Bukhari U, Husain AN, Toth PT, Kim G, Earley J, McNally EM: S100A12 in vascular smooth muscle accelerates vascular calcification in apolipoprotein E-null mice by activating an osteogenic gene regulatory program. Arterioscler Thromb Vasc Biol 2011;31:337-344.

22 Gawdzik J, Mathew L, Kim G, Puri TS, Hofmann Bowman MA: Vascular remodeling and arterial calcification are directly mediated by S100A12 (EN-RAGE) in chronic kidney disease. Am J Nephrol 2011;33:250-259.

23 Yan L, Mathew L, Chellan B, Gardner B, Earley J, Puri TS, Hofmann Bowman MA: S100/ calgranulin-mediated inflammation accelerates left ventricular hypertrophy and aortic valve sclerosis in chronic kidney disease in a receptor for advanced glycation end products-dependent manner. Arterioscler Thromb Vasc Biol 2014;34:1399-1411.

24 Kim HS, Chung W, Kim AJ, Ro H, Chang JH, Lee HH, Jung JY: Circulating levels of soluble receptor for advanced glycation end product are inversely associated with vascular calcification in patients on haemodialysis independent of S100A12 (EN-RAGE) levels. Nephrology (Carlton) 2013;18:777-782.

25 Basta G, Sironi AM, Lazzerini G, Del Turco S, Buzzigoli E, Casolaro A, Natali A, Ferrannini E, Gastaldelli A: Circulating soluble receptor for advanced glycation end products is inversely associated with glycemic control and S100A12 protein. J Clin Endocrinol Metab 2006;91:4628-4634.

26 Myles A, Viswanath V, Singh YP, Aggarwal A: Soluble receptor for advanced glycation endproducts is decreased in patients with juvenile idiopathic arthritis (ERA category) and inversely correlates with disease activity and S100A12 levels. J Rheumatol 2011;38:19941999.

27 Raggi P, Callister TQ, Shaw LJ: Progression of coronary artery calcium and risk of first myocardial infarction in patients receiving choles- terol-lowering therapy. Arterioscler Thromb Vasc Biol 2004;24:1272-1277.

28 Raggi P, Cooil B, Shaw LJ, Aboulhson J, Takasu J, Budoff M, Callister TQ: Progression of coronary calcium on serial electron beam tomographic scanning is greater in patients with future myocardial infarction. Am J Cardiol 2003;92:827-829.

29 Sigrist MK, Taal MW, Bungay P, McIntyre CW: Progressive vascular calcification over 2 years is associated with arterial stiffening and increased mortality in patients with stages 4 and 5 chronic kidney disease. Clin J Am Soc Nephrol 2007;2:1241-1248.

30 Block GA, Spiegel DM, Ehrlich J, Mehta R, Lindbergh J, Dreisbach A, Raggi P: Effects of sevelamer and calcium on coronary artery calcification in patients new to hemodialysis. Kidney Int 2005;68:1815-1824.

31 Ozkok A, Caliskan Y, Sakaci T, Erten G, Karahan G, Ozel A, Unsal A, Yildiz A: Osteoprotegerin/RANKL axis and progression of coronary artery calcification in hemodialysis patients. Clin J Am Soc Nephrol 2012;7:965-973.

32 Nitta K, Akiba T, Uchida K, Kawashima A, Yumura W, Kabaya T, Nihei H: The progression of vascular calcification and serum osteoprotegerin levels in patients on long-term hemodialysis. Am J Kidney Dis 2003;42:303309. 